\title{
Newly diagnosed, treatment-naive patients with rheumatoid arthritis have early abnormalities of vascular and myocardial function
}

\author{
Bara Erhayiem², Adam K McDiarmid ${ }^{2}$, Peter P Swoboda ${ }^{2}$, Ananth Kidambi ${ }^{2}$, David P Ripley ${ }^{2}$, Tarique A Musa ${ }^{2}$, \\ Laura E Dobson², Pankaj Garg², Jacqueline Andrews'1, John P Greenwood², Maya H Buch', Sven Plein ${ }^{2}$
}

From 18th Annual SCMR Scientific Sessions

Nice, France. 4-7 February 2015

\section{Background}

Rheumatoid arthritis (RA) is a common autoimmune disease. Mortality is increased compared to the general population largely due to increased cardiovascular disease (CVD). Immune dysregulation and systemic inflammation are thought to be associated with this increased risk. CMR can provide an assessment of CVD, including myocardial and vascular morphology and function, but it is unknown which CMR measurements are most sensitive to detect early CVD.

\section{Objectives}

To determine CV manifestations of RA using CMR in newly diagnosed, treatment-naive patients compared with matched controls.

\section{Methods}

Fifty-two RA patients fulfilling ACR/EULAR classification RA criteria, without CVD history, underwent CMR at 3.0T (Philips Achieva TX). They had symptoms for less than 1 year, had not yet received therapy with any disease modifying anti-rheumatic drugs, disease activity score (DAS28) $\geq 3.2$ and at least one RA poor prognostic factor. 30 healthy controls were matched by age, sex and blood pressure. Standard balanced steady state free precession (SSFP) cine images were acquired and LV dimensions calculated. Strain analysis was performed by tissue-tagging using a spatial modulation of magnetization pulse sequence. For aortic distensibility (AD), multi-phase SSFP cine images (50 phases) were acquired in a plane transverse to the ascending aorta at the level

\footnotetext{
${ }^{2}$ Multidisciplinary Cardiovascular Research Centre \& Leeds Institute for Cardiovascular and Metabolic Medicine, University of Leeds, Leeds, UK Full list of author information is available at the end of the article
}

of the pulmonary artery bifurcation. Aortic contours were drawn by manual planimetry of the endovascularblood pool interface at the times of minimal and maximal distension. Native and 15 minute post-contrast T1 maps were generated from mid-LV short axis using a modified 3,3,5 Look-Locker inversion sequence to calculate extra-cellular volume fraction (ECV).

\section{Results}

Participant characteristics are presented in Table 1.

Aortic distensibility was reduced in RA patients compared to controls (mean $\pm \mathrm{SD}, 3.23 \pm 1.610^{-3} \mathrm{mmHg}^{-1}$ versus $\left.4.99 \pm 1.810^{-3} \mathrm{mmHg}^{-1}, \mathrm{p}=0.001\right)$. Other measures of arterial stiffness including aortic stiffness index, compliance and strain showed differences with similar significance levels. Left ventricular remodelling was not different in the RA group compared with controls, but $S^{\prime}$ was lower in RA (mean \pm SD, $0.99 \pm 0.22$ Seconds $^{-1}$ versus $1.13 \pm 0.16$ Seconds $\left.^{-1}, \mathrm{p}=0.007\right)$ which may signify sub-clinical reduction in myocardial performance. Evidence for overt inflammation/fibrosis was seen in 4 patients with areas of focal non-ischaemic patterns of LGE, but native T1 and ECV was not different between the groups. See Table 2.

\section{Conclusions}

Early abnormal subclinical changes in vascular and myocardial function exist in newly diagnosed, treatmentnaive RA patients, without overt changes in ventricular performance and geometry. The natural history of these observations and implications in the wider management of RA warrant further investigation. 
Table 1 Participant characteristics according to Rheumatoid Arthritis status.

\begin{tabular}{|c|c|c|c|}
\hline Characteristic & $\mathrm{RA} n=52$ & Control $n=30$ & $p$-value \\
\hline Age, years & $49.3 \pm 14.1$ & $46.7 \pm 11.4$ & 0.39 \\
\hline Female gender; $\mathrm{n}(\%)$ & $34(65)$ & $15(50)$ & 0.18 \\
\hline Body surface area, $\mathrm{m}^{2}$ & $1.87 \pm 0.22$ & $1.9 \pm 0.21$ & 0.43 \\
\hline Systolic blood pressure, $\mathrm{mmHg}$ & $124 \pm 17$ & $125 \pm 16$ & 0.80 \\
\hline Pulse pressure, $\mathrm{mmHg}$ & $54 \pm 13$ & $53 \pm 13$ & 0.68 \\
\hline $\mathrm{ESR}, \mathrm{mm} / \mathrm{h}$, median (IQR) & $31.5(34)$ & - & - \\
\hline CRP, mg/L, median (IQR) & $6.4(34)$ & - & - \\
\hline ACPA, n (\%) & $44(85)$ & - & - \\
\hline $\mathrm{RF}, \mathrm{n}(\%)$ & $41(79)$ & - & - \\
\hline DAS28 & $5.8 \pm 1.7$ & - & - \\
\hline
\end{tabular}

Data presented as mean $\pm S D$ unless otherwise stated. $A C P A=$ anti-citrullinated peptide antibody, $C R P=C$-reactive protein, DAS= Disease activity score, ESR= Erythrocyte sedimentation rate, $\mathrm{RA}=$ Rheumatoid arthritis, $\mathrm{RF}=$ Rheumatoid factor.

Table 2 CMR findings between RA patients and controls.

\begin{tabular}{|c|c|c|c|}
\hline Measurement & $\mathrm{RA} n=52$ & Control $n=30$ & p-value \\
\hline Aortic distensibility, $10^{-3} \mathrm{mmHg}^{-1}$ & $3.23 \pm 1.6$ & $4.99 \pm 1.8$ & 0.001 \\
\hline Aortic compliance & $11.5 \pm 4.7$ & $16.7 \pm 5.2$ & $<0.001$ \\
\hline Aortic strain & $-0.16 \pm-0.07$ & $-0.25 \pm-0.06$ & $<0.001$ \\
\hline Aortic stiffness index, $B$ & $4.53 \pm 2.69$ & $2.33 \pm 0.71$ & 0.001 \\
\hline LVEDV, ml & $153 \pm 36$ & $167 \pm 31$ & 0.082 \\
\hline LVEF, \% & $60 \pm 6$ & $61 \pm 4$ & 0.504 \\
\hline LV Mass, $g$ & $83 \pm 23$ & $90 \pm 4$ & 0.216 \\
\hline LV Mass/LVEDV, g/ml & $0.55 \pm 0.11$ & $0.54 \pm 0.11$ & 0.696 \\
\hline$S^{\prime}$, Seconds $^{-1}$ & $0.99 \pm 0.22$ & $1.13 \pm 0.16$ & 0.007 \\
\hline Peak twist, degrees & $15.6 \pm 4.2$ & $14.16 \pm 4.7$ & 0.118 \\
\hline Torsion, degrees & $13.9 \pm 3.6$ & $13.1 \pm 4.1$ & 0.211 \\
\hline LGE, n (\%) & $4(8)$ & $0(0)$ & 0.044 \\
\hline Native T1, ms & $1179 \pm 45$ & $1160 \pm 50$ & 0.081 \\
\hline $\mathrm{ECV}, \%$ & $27.0 \pm 3.9$ & $25.8 \pm 2.6$ & 0.213 \\
\hline
\end{tabular}

Data presented as mean $\pm \mathrm{SD}$ unless otherwise stated. $\mathrm{ECV}=$ extra-cellular volume, $\mathrm{EDV}=$ End-diastolic volume, $\mathrm{EF}=\mathrm{Ejection}$ fraction, $\mathrm{LGE}=\mathrm{Late}-\mathrm{gadolinium}$ enhancement, LV=Left ventricle, $S^{\prime}=$ Peak systolic strain rate.

\section{Funding}

The study is funded by an EME project grant (11/117/ 27).

JPG and SP receive a research grant from Philips Healthcare.

SP is funded by British Heart Foundation fellowship (FS/10/62/28409).

\section{Authors' details}

'Leeds Institute of Rheumatic \& Musculoskeletal Medicine, University of Leeds, Leeds, UK. ${ }^{2}$ Multidisciplinary Cardiovascular Research Centre \& Leeds Institute for Cardiovascular and Metabolic Medicine, University of Leeds, Leeds, UK.

Published: 3 February 2015
doi:10.1186/1532-429X-17-S1-P285

Cite this article as: Erhayiem et al:: Newly diagnosed, treatment-naive patients with rheumatoid arthritis have early abnormalities of vascular and myocardial function. Journal of Cardiovascular Magnetic Resonance 2015 17(Suppl 1):P285.

\section{Submit your next manuscript to BioMed Central} and take full advantage of:

- Convenient online submission

- Thorough peer review

- No space constraints or color figure charges

- Immediate publication on acceptance

- Inclusion in PubMed, CAS, Scopus and Google Scholar

- Research which is freely available for redistribution

Submit your manuscript at www.biomedcentral.com/submit 